\title{
"Beyond reason and vanity?"”: some issues in academic journal publication in Library and Information Studies ${ }^{2}$
}

\author{
Christine Stilwell \\ Information Studies, School of Sociology and Social Studies, University of KwaZulu-Natal, \\ Private Bag XOI, Scottsville, Pietermaritzburg, South Africa. \\ stilwell@ukzn.ac.za
}

\begin{abstract}
Received:20th October 2004
Accepted: 25th January 2006

This review of some journal and monograph literature on scholarly publishing discusses certain issues in the research and publishing landscape. The results of a case study of selected South African Library and Information Science journals are presented and they reveal acceptance rates before and after revision, and rejection rates for manuscripts. The results are used to support the value of the revision and resubmission of research manuscripts.
\end{abstract}

\section{Introduction and background}

The article comprises a descriptive review of certain issues in academic journal publishing in Library and Information Science (LIS). The discussion is related to the findings of a case study of selected local journals in the field which was carried out by the author. The case study reveals acceptance rates for manuscripts before and after revision and resubmission, and rejection rates. In this way the value of persevering seemingly "beyond reason and vanity" (Murray 2005:1) with the revision and resubmission of research manuscripts is supported.

Two research methods were used for the study upon which the article is based: the descriptive review of certain issues in the literature and the case study of selected South African journals in LIS. The literature for the descriptive review was identified using the electronic databases available on the local academic library website and from an alerting service provided by the subject librarian for information studies. The selection was checked against bibliographies of recent related sources but is not intended to be seen as comprehensive. The case study rationale, data collection methods, results and recommendations are reported and discussed below but first important elements in the background to the study require elucidation, commencing with defining research and publication and their primary goals.

\section{Research and publication and their primary goals}

In sketching the research and publication landscape, definitions of research which embrace the academic and professional dimensions are presented.

\subsection{Research}

Turner (2002:3) defines research as

any systematic effort to generate new information, create new knowledge, or produce new interpretations of existing knowledge or information, suggesting attention to method and exactitude in obtaining and analysing results.

McNicol and Dalton (2004:167) cite the Higher Education Funding Council for England (1994) definition of academic research which gives specific examples of the contexts in which research outcomes would be used. Academic research is ...original investigation undertaken in order to gain knowledge and understanding. It includes work of direct relevance to the needs of commerce and industry, as well as to the public and voluntary sectors; scholarship ... and the use of existing knowledge in experimental development to produce new or substantially improved materials, devices, products and processes.

Research in LIS is seen by Powell, Baker and Mika (2002:49) as necessary

I. The phrase is borrowed from Murray (2005:I) and echoes Skinner's "Beyond freedom and dignity".

2. An earlier version of this paper under a different title provided the Keynote address to the DLIS \& LISA $4^{\text {th }}$ Conference, University of Zululand, kwaDlangezwa, 8 September 2003

3. Professor and Acting Academic Co-ordinator, Information Studies, School of Sociology and Social Studies, University of KwaZuluNatal, Private Bag XOI, Scottsville, Pietermaritzburg, South Africa. E-mail stilwell@ukzn.ac.za 
to create new knowledge and thereby contribute to the growth of LIS as profession or discipline ... to improve problem-solving and decision making in the workplace, to make professional practitioners critical consumers of research literature, and to better equip librarians to provide optimal information services to researchers in other fields.

Within higher education institutions research is viewed by McNicol and Dalton (2994:167) as serving to maintain "the currency and vitality" of modules and to enrich students' learning. For staff, involvement in research can develop knowledge, skills, professional reputations as well as helping the institution to attract students and staff of a high calibre. Research also enhances knowledge in the field more generally for the profession and in this case the LIS community as a whole. LIS is both an academic discipline and a field of professional practice, with teaching representing the interface between the two and with "teaching and research in LIS ... intrinsically linked" (McNicol and Dalton 2004: 174).

Murray (2005:20) refers to categories of research experience and urges authors to "work out where you are coming from, what definition of research is meaningful to you ..." In defining the framework for research and publication which lies behind such exploration the article draws on three perspectives through which to examine the practice of research (Cohen, Manion and Morrison 2000:3). These are (i) scientific method and positivistic methodologies (ii) naturalistic and interpretive methodologies and (iii) methodologies from critical theory. Neuman (2003:69-94) uses the same three perspectives in the social sciences, adding the additional approaches of feminist and postmodern research. Dick (1993) also refers to the three initial perspectives similarly to review South African research in LIS but identifies his second approach as constructivist.

Cohen, Manion and Morrison (2000:3) draw on an important notion from Hitchcock and Hughes to enlarge on the need to situate research practice using a framework of this sort. Their statement has been further glossed (see square brackets) by the author using Case (2002:133). Cohen, Manion and Morrison (2000:3) go on to explain that "ontological assumptions [about the nature of reality], give rise to epistemological assumptions [about how we know]; these in turn give rise to methodological considerations [how we find out] and these, in turn give rise to issues of instrumentation and data collection". Research is concerned with "understanding the world and that this is informed by how we view our world/s, what we take understanding to be and what we see as the purposes of understanding..." Case (2002:132) explains that "just as a pyramid depends on its foundations to provide stability for the rest of the structure, scholars rely on basic assumptions regarding the nature of reality and the purposes and methods of investigation".

Case (2002:132) cites Dervin who identifies some perspectives and methodologies which embrace different philosophies, methods, research traditions and theory. These are listed here but not elucidated:

...symbolic interaction, pragmatics, systems theory, qualitative studies, cultural studies, hermeneutics, political

economy, phenomenology, constructivism, interpretive anthropology, transactionism, contextual psychology,

ethnography, perspectivism, situationalism and postmodernism.

Case, noting that theories are explanations and or generalisations that seek to explain the relationships among various phenomena, offers a hierarchy of theory with paradigm and equivalent concepts at the highest level; grand or formal theory next, followed by theory of the middle-range or grounded theory, and then observations (see Figure I):

\section{Paradigm/Perspective/Tradition}

\section{Grand/Formal Theory}

\section{Middle-Range/Grounded Theory}

\section{Observations}

Figure 1 A hierarchy of theory (Case 2002:134)

It is not the intention of the article to further explain these approaches to research inquiry as researchers are familiar with the ontological, epistemological and methodological premises of their approach and of the strengths and weaknesses of the last mentioned for their purpose (Cohen, Manion and Morrison 2000:3-45).

Turner (2003:9) has called LIS "a complex and human-mediated discipline". Recognising this the article follows the approach adopted by Cohen, Manion and Morrison (2000:45) who quote Merton and Kendall to make the point that social scientists have abandoned "the spurious choice between qualitative and quantitative data: they are concerned rather with that combination of both that makes use of the most valuable features of each. The problem becomes one of determining at which points they should adopt the one, and at which the other approach". It is important to note that 
studies often use mixed methods employing both quantitative and qualitative data. Understanding the approach or combination of approaches used for research contributes to the logic and coherence of the research.

Cohen, Manion and Morrison (2000:3,5) suggest that "People have long been concerned to come to grips with their environment and to understand the nature of the phenomena it presents to their senses". There are many types of research, for instance those that use primary data or analyse existing data, or a combination of these two types. In selecting an appropriate research design among those to be considered are surveys, experiments, case studies, programme evaluation and ethnographic studies. Others are discourse analysis, content analysis, textual criticism, historical method, philosophical analysis, conceptual analysis, literature reviews, theory building and statistical modelling (Mouton 2001:143-180). In a well considered and carefully designed study the perspective, theoretical framework, methodology and tools will be in harmony.

The primary goal of research is the production of information and knowledge. Ocholla (2000:1I) argues, however, that research is only complete when it is published, thereby stressing the importance of publication. Day (2000:7) points out that "Research funding has become increasingly tied to published research".

\subsection{Publication}

Publication is publicly documenting, or sharing important findings that research has generated with a wider audience, and testing the contribution by laying it open to scrutiny both in the referee process and in wider reading of a journal. Gorman cited in Calvert and Gorman (2002:2) suggests that contributors to journals, one of the many forms of publication, write for various reasons. Calvert and Gorman suggest that authors write

to disseminate new research findings or ideas. The publication of a paper establishes precedents in the formation of new knowledge, and it puts new information in the professional domain where it can be scrutin ised, criticized and either accepted or rejected. It may then contribute to further discourse. The author also makes personal gains by adding to a list of publications that can be used for tenure and promotion, for gaining professional acceptance that may lead to speaking engagements, consultancy work, perhaps even awards (Calvert and Gorman 2002:2).

McNicol and Dalton (2004:176) argue for the sharing of ideas and urge researchers to ensure that their findings are disseminated in "scholarly publications, specialist publications and professional journals with a wide audience including fellow researchers, funders, policymakers and practitioners". Murray (2005:I) suggests, however, echoing Skinner's phrase "Beyond freedom and dignity" that writing for academic journals cannot be reduced to a "set of professional imperatives" and that there must also be personal motivations for publishing in this way. She suggests that the dominant characteristic of academic writers is in fact their persistence which, as much as anything else, keeps them going when others have given up.

McNicol and Dalton (2004:176) argue for the use of alternative forms of dissemination, other than research reports, for instance, workshops, practice guidelines, or articles written by journalists working together with researchers. They raise the issue of the available options in terms of research output.

\section{Forms of publication}

Publications take many forms and appear in a variety of media. Attention to selecting suitable information products for a particular purpose and audience is an important area to consider when publishing (Orna 1995). The options depend to some extent on the field. Research guidelines for a local university list the following acceptable formats: refereed conference proceedings; journal articles, books, chapters in books and edited books, patents as well as creative contributions, both local and international, for disciplines such as the Fine and Performing Arts (University of KwaZuluNatal. 2005). Of the commonly used channels for research and publication this article has selected the journal article upon which to focus as it is common in most disciplines.

Journals can be local, regional and international and the choice of the journal targeted depends on many factors which have been clearly elucidated by Darch and Underwood (2005:3), and some of which are discussed below. Murray (2005:39) notes the popular view that one should aim to publish in the most prestigious journals in one's field. This choice depends on the quality of one's work, its relevance to the research community targeted by the journal and so on. How are the top journals identified?

\section{Criteria for the evaluation of journal and journal articles quality}

The traditional approach to measuring journal quality uses quantitative measures such as circulation, number of times cited in the literature, coverage by indexing services and so on (see below). Garfield's work (1994a,b) has established citation analysis as an almost unquestioned measure of quality (Calvert and Gorman 2002). 
Thomson Scientific (2005), formerly known as Thomson ISI or the Institute of Scientific Information provides access to information for researchers and scholars worldwide. The Journal Citation Reports (JCR) offers "quantitative tools for ranking, evaluating, categorizing, and comparing journals" (Garfield 1994a). One of these is the Journal Impact Factor (JIF) which identifies core journals in all subject areas and it is used as a predictor of research impact. The impact factor is "a measure of the frequency with which the 'average article' in a journal has been cited in a particular year or period". The JCR impact factor which is updated annually is a ratio between citations and the recent citable items which have been published (Garfield 1994a). The impact factor is used to assess the significance of citation frequencies and is intended to eliminates bias such as favouring "large journals over small ones, or frequently issued journals over less frequently issued ones, and of older journals over newer ones" (Garfield 1994a). Garfield does caution that the data need to be used sensibly in evaluating journals and that they should be used in conjunction with other measures such as peer review. He also notes that there are differences between disciplines. Further, articles in review journals tend to have higher impact factors than typical research articles because they serve as "surrogates" for earlier literature. For this reason the JIF should be used "discreetly" (Garfield 1994a). Testa (2004) notes that Social Sciences journals are subjected to undergo the same thorough evaluation as Natural Science journals: "publishing standards, editorial content, international diversity, and citation data are all considered" but that in general, Impact Factors and overall citation rates in the Social Sciences are lower than those in the Natural Sciences. These factors all need consideration but the JCR as a whole does provide quantitative measures and journal-to-journal relationships within scientific literature as Garfield (1994b) argues. To what extent the JIF is used "discreetly" is explored by Darch and Underwood (2005) and some of their arguments are referred to below.

Harnad, Carr, Brody and Oppenheim (2004:2) argue that there is a hierarchy of peer-reviewed journals "from those with the highest quality standards (and hence usually highest rejection rates and impact factors) at the top, grading all the way down to the lowest quality journals at the bottom".

Journal ranking and its relation to positive institutional ratings is supported by Harnad, Carr, Brody and Oppenheim (2004) and Holmes and Oppenheim (200I). The latter argue that many studies demonstrate a strong correlation between citation counts and other ratings of academic excellence. They examine, for instance, the British Higher Education Council's Research Assessment Exercise (RAE) which grades the output of university departments and they compare these measures with rankings based on citation counts for authors.

This approach to evaluating journals continues to predominate in spite of other work, for example, studies by Altmann and Gorman (1999) and Calvert and Gorman (2002), questioning the real value of quantitative measures in determining the quality and usefulness of journal literature. Gorman suggested six criteria for the evaluation of submissions to LIS journals and Calvert and Gorman used these in their 2002 study. The criteria are presented here as ranked by their study in descending order of importance. These are the extent to which the manuscripts exhibit the following:

- New information or data

- Acceptable research design

- Level of scholarship

- Theoretical soundness

- Advancement of knowledge

- Appropriate methodology and analysis (Calvert and Gorman 2002:3).

With regard to scholarly quality these authors examined the quality of analysis applied to the content and the author's ability to generate new knowledge. For theoretical soundness they sought some evidence of the use of theory and at best the use of "multiple theories appropriate to the context". The use of theory, they note, is not a "strong point in the LIS literature" (Calvert and Gorman 2002:4-5,6).

In some countries like South Africa there is a list of journals in which academics publish if their contributions are to count for various rewards (Murray 2005:43). Ocholla (2004:4) observes that in South Africa "publication in special peerrefereed government subsidized articles is increasingly frequent perhaps because of financial gain and recognition afforded by the country". Ocholla (2005: 15) noted that R7I 000 for each article published in one of these journals went to the institution of the author's affiliation. Similarly McNicol and Dalton (2004:173) report that the Research Assessment Exercise "allows quality ratings according to how much work is judged to reach national or international levels of excellence". Hence the RAE is important for securing funding and raising the profile of the institution. These authors also raise the consideration of national or international profiles for journals.

The lists of approved LIS journals which are used in South Africa by the Department of Education have been subjected to critical scrutiny by Darch and Underwood (2005:1-10) in an article that performs an important scene setting role for this article. These authors argue that 'the identification of research as being of 'high quality' - is a complex and contentious matter, differing between disciplines, and for practical purposes some short cuts are inevitably taken" (Darch and Underwood 2005; I). They conclude on a note of great caution, that because of various inadequacies in, and 
additional benefit of improving impact on citation counts. Ocholla (2004:I) for instance, notes that Library Science and Information Science accounted for only $4.4 \%$ of the publication output in the social sciences in 2000 in ISI listings. The counts for locally produced LIS research material are likely to be lower as can be inferred from Darch and Underwood (2005:3). Spurret offers a means of addressing the generally low ISI citation ratings for local authors.

Booth (2003:10) argues for the importance of what Bayley and Eldredge (whom he cites) have called structured abstracts; abstracts structured around prespecified sections such as subjects, intervention, outcomes, methods, results and conclusions. They have been shown to improve retrieval and enable rapid assimilation. Research commissioned by the British Library (Hartley cited by Booth 2003:10) suggests that while common in medical journals these abstracts are feasible for use in social sciences research literature including librarianship.

\section{Reasons for publishing in academic journals}

Some motivations for publishing in academic journals have already been noted, for instance, Murray (2005) and Ocholla (2004) refer to the South African research publication incentive system. Murray provides a comprehensive summary of the reasons for publishing specifically in academic journals. Among these are:

- Career progression - moving up to the next rung on the ladder

- Gaining recognition for work one has done

- Stopping someone else taking credit for one's work or using one's materials

- Helping one's students to gain recognition for their work

- Learning how to write to a higher standard

- Contributing to knowledge

- Building one's institution's status

- Developing a profile (Murray 2005:14) or research niche.

Some reasons are more altruistic than others, such as helping students to get published which can assist them to get a job and or professional advancement. Publishing also plays a role in what is commonly known as networking.

Zeldin (2005:I) describes networking as "a method for giving the individual a competitive advantage among professionals who are otherwise equal in education, competence and experience". Successful networkers supposedly not only reinforce their own skills with those of other colleagues but also have links with others who are not themselves linked to one another. In the academic realm these networked circles are referred to as the invisible college. Much of this communication takes place informally and person to person, either face to face or via the information and communication technologies such as electronic mail. Murray (2005:2) refers to these networks when she states that "networks, collaborations and beneficiaries, in a variety of senses, are positioned in the research process at more than conceptual level”.

Lamoral (200I:184) supports the importance of these networks for researchers, reporting that personal contacts are a highly valued information source among researchers at a forestry institute attached to a local university. Turner (2002:910) identifies the value of professional networking by LIS practitioners, including opportunities offered for networking by conferences, meetings, electronic mail listservs and intra-colleague information sharing. She reports requests from LIS practitioners for regular bulletins reporting on research in progress, as well as for a national database or central research register to which all libraries could both refer and contribute. An important ingredient for networking is nicheing oneself, for example, on expert lists, by establishing a reputation for working in a particular field or using a particular approach to research. The next section deals with reasons for not publishing.

\section{Reasons for not publishing and some possible remedies}

Most authors have experienced rejection of a manuscript and have had to deal with what may seem like personal rejection. Fear of failure is a common reason for not publishing (Day 2000:I I; Murray 2005:23). In addition many excellent researchers have difficulty getting published because they have to learn the skills of scholarly writing unassisted (Potter 200I:13). Day (2000:4) suggests, however, that the writing process is as important as the finished product and that "writing and revising are an education in themselves".

The following section addresses some strategies for overcoming barriers to scholarly publishing. It is not intended to be comprehensive as other sources provide such coverage, for instance, Darch and Underwood (2005) and Ocholla (2005) raise many important considerations and Weller (200I) provides a systematic review of the peer review process, which is beyond the capacity of a single journal article.

\subsection{Understanding the refereeing process}

Booth (2003:12) praises Weller (200I) for extending an evidence-based model to her systematic review of empirical studies of the peer review process from 1945 to 1997. Weller (2001:2) outlines the path of a manuscript through the editorial peer review process. 
The norm in peer review is two to three referees (Alexander 200I:7). In LIS double blind reviewing, in which the identity of neither the authors nor the referees is known to the other, is common (Weller 200I:2।2).

Who are the peer reviewers? Weller (200I:154) suggests that they are those who have expertise on the subject under scrutiny, are willing to spend time to be thorough and make the paper better, can render an informed, unbiased decision and have no conflict of interest with authors, subject or product. Moran (1998) explores some of the problems around peer review, particularly anonymous or blind peer review while Murray (2005:3I) raises a controversial view when she argues that many factors affect the role and status of the writer in academia: "academic writing is not neutral. It is gendered, raced, classed and, therefore potentially discriminatory in many ways". The community of academic writers, she argues, is diverse, while the community of editors and reviewers may be less diverse. Murray (2205: 188) agrees, however, that reviewers do generally give papers a thorough critique and that one can invariably improve a paper by taking their views into account. Alexander offers practical insights into the role of the referees who address:

the nature of your question, how you have linked it to the existing theory and literature, the method and analysis of the study, and your interpretation of the results. These lead to dreaded 'So what?' questions. 'Is this an interesting and important question? Does this work add to the existing knowledge in the field? Is the research well done? Does the work communicate these things to the reading audience?'(Alexander 200I:7).

Until the paper has been peer reviewed one may not be sure that one has in fact made a contribution (Murray 2005:29).

8.2 Rejection rates and the commonly cited reasons for rejection

Murray (2005:198) lists common reasons why papers are rejected for publication, together with how to deal with the criticisms. Weller (200I:52) describes actual reasons for rejecting manuscripts including LIS manuscripts. She cites Landwith to show that the most common problems are "duplicates other work", "poorly written/presented" and "methodological problems" and Hernon, Smith and Croxen who also identify "duplicates other work" as the most frequently occurring problem. According to Weller (200I:56) the mean rate of rejection for Library Science articles by journals in 1976, 1988, 1992 and 1996, based on studies which reported on these years was $66 \%$. Higher rejection rates were found in various other disciplines.

The decision to accept, reject or ask for revision of a manuscript is the task of the editor who communicates the decision to the author and recommends appropriate action, often with reference to the reports of the referees which are forwarded to the author (Moran 1998). An option commonly offered to authors is that of revising and resubmitting (R\&R) the manuscript.

\subsection{Acceptance of an article after R\&R}

Outright acceptance by a top journal is rare as the case study results show (see below) but a request from the editor to revise and resubmit (R\&R) is common. Alexander (200I:9) argues that "R\&R is good. Most manuscripts need to be revised, and many need to be revised more than once" but she notes that many editors are surprised at the number of manuscripts which they select for R\&R that are never returned for the second round of review.

In addition manuscripts that are rejected outright by one journal may be accepted by another. Weller reports in her study (200I:64) across many disciplines, that between $28 \%$ and $85 \%$ of rejected manuscripts, that is, an average of $51 \%$ were eventually published elsewhere. She also reported in an earlier 1996 study of biomedicine (Weller 2001:68) that $44 \%$ of the manuscripts that had been rejected by a journal in the more select set of journals had been accepted by another journal in the same set. In a similar study which tracked 10 Biochemist's manuscripts, $70 \%$ of those initially rejected were later accepted by a journal of higher rank.

It is clear from the literature cited that many manuscripts are accepted either by the initial journal or a subsequent journal after changes have been made. An examination of the results of the case study elucidates the former with reference to local LIS-related findings.

\section{Case study of selected LIS journals in South Africa ${ }^{4}$}

\subsection{Purpose and scope}

Ocholla's (2004:3) infometric study noted that I54 South African authors published 498 articles in 89 LIS journal between 1993 and May 200I. Of the publications 65\% appeared in local or South African journals. The most commonly used journals were the South African Journal of Library and Information Science (38\%), Mousaion (16\%) and Innovation: a journal of appropriate library and information work in southern Africa (6\%). In order to pursue more specific feedback about publication patterns in local journals concerning such factors as acceptance of an article without changes, acceptance after revision and resubmission, and rejection rates, the author surveyed four LIS journals targeted by local authors for their LIS

4. A copy of the instrument is available from the author of the article. 
publications. Five journals were initially targeted but one editor did not respond. The results for the other four are reported here.

\subsection{Data collection methods and analysis of the data}

The survey questions were generated from the literature and in particular from comment in the literature about the importance of revising and resubmitting papers (Day 2000; Murray 2005). Such views were part of the motivation for the article; to probe the acceptance and rejection rates of journals commonly targeted by South African researchers in LIS. The selection of journals was based on Ocholla's (2004) list and included a popular regional journal in LIS, as well as a local online journal, that is five journals in all. The four local journals were on the lists of journals recognized by the national department of education for research incentive purposes and comprise the full complement of research journals for LIS in the country (see also, for verification, the list in Table I in Darch and Underwood (2005:8-10).

The identity and contact details of the editors were confirmed using the journal websites and an electronic mail request explaining the survey was sent to the editors in July 2005. Editors were assured that the journals would not be linked by name to the results reported. Statistics were requested for the last two years only; 2004 and 2005 until the time of the survey. The brevity of the period covered was intended to make the task less onerous for the editors so as to encourage a positive response.

Responses from two journals were received promptly and reminders were sent to the others. All except one editor responded, thus giving an $80 \%$ response rate. One editor sent a response to a Department of Education survey (see also Ocholla 2005:10) which contained information in a slightly different configuration. Another responded to the questionnaire and also sent a report on the journal that had been prepared for the association which produces the journal. No response was received from the editor of the regional journal.

Responses from the journal editors were scrutinized for data cleansing purposes. The data was analysed and frequencies and percentages were calculated. The latter were given, in spite of the small population size as a useful relative measure.

\subsection{Findings and recommendations of the case study}

Responses for the four journals whose editors responded are reflected below. The journal names are not reflected in the tables. Journals I and 3 have two issues per year, journal 2 has two, with three in 2005, journal 4 has four issues per year.

Table I Journal manuscripts (ms) received, accepted, accepted after revision and rejected for four South African journals: 2004-2005

\begin{tabular}{|c|c|c|c|c|c|c|c|c|c|c|c|c|c|c|}
\hline \multirow{3}{*}{$\begin{array}{l}\text { Journal } \\
\text { J }\end{array}$} & \multicolumn{2}{|c|}{ Manuscripts received } & \multicolumn{4}{|c|}{ Ms accepted with no revision } & \multicolumn{4}{|c|}{ Ms accepted after revision } & \multicolumn{4}{|c|}{ Ms rejected } \\
\hline & \multirow{2}{*}{$\begin{array}{l}2004 \\
18\end{array}$} & \multirow{2}{*}{$\begin{array}{l}2005 \\
14\end{array}$} & \multicolumn{2}{|c|}{2004} & \multicolumn{2}{|c|}{2005} & \multicolumn{2}{|c|}{2004} & \multicolumn{2}{|c|}{2005} & \multicolumn{2}{|c|}{2004} & \multicolumn{2}{|c|}{2005} \\
\hline & & & 3 & $17 \%$ & 0 & $0 \%$ & 9 & $50 \%$ & 13 & $92 \%$ & 6 & $33 \%$ & 1 & $7 \%$ \\
\hline J2 & 20 & 22 & 1 & $5 \%$ & 2 & $9 \%$ & 13 & $65 \%$ & 12 & $55 \%$ & 6 & $30 \%$ & 8 & $36 \%$ \\
\hline J3 & 20 & 25 & 0 & $0 \%$ & 1 & $4 \%$ & 14 & $70 \%$ & $16 *$ & $64 \%$ & 7 & $35 \%$ & 6 & $24 \%$ \\
\hline JI-3 & 58 & 61 & 4 & $7 \%$ & 3 & $5 \%$ & 36 & $62 \%$ & 41 & $67 \%$ & 19 & $33 \%$ & 15 & $25 \%$ \\
\hline Total & \multirow{2}{*}{\multicolumn{2}{|c|}{119}} & \multicolumn{4}{|c|}{$7(6 \%)$} & \multicolumn{4}{|c|}{77 (65\%) } & \multicolumn{4}{|c|}{$34(29 \%)$} \\
\hline J4** & & & \multicolumn{4}{|c|}{$65 \% * * *$} & \multicolumn{4}{|c|}{ |5\%***** } & \multicolumn{4}{|c|}{$20 \%$} \\
\hline
\end{tabular}

*Third issue was still pending.

**Statistics for this journal were available for 2002-3 and had been consolidated. The categories are also slightly different as noted below.

**** After no or minor revisions

***** After significant revisions

Of the 119 manuscripts submitted to journals I to 3 , only $6 \%$ were initially accepted outright, meaning $94 \%$ were referred back or rejected. This finding is in keeping with Alexander's finding $(2001: 10)$ that most journals work with a less than $15 \%$ rate of acceptance. For journals I to 3, $29 \%$ of the manuscripts were rejected, with $20 \%$ being rejected by journal 4.

Of the manuscripts $65 \%$ were accepted after revision and resubmission, with $65 \%$ of journal 4 's manuscripts being accepted after minor revision and $15 \%$ after more substantial revision, giving an aggregated total of $80 \%$ for accepted R\&R manuscripts for this journal.

Notable for all journals is the generally low rate of acceptance without any revision. In the case of journal 4 the figure is high as the available statistics included manuscripts requiring minor revision. Consequently the total for this journal for acceptance after revision is predictably low. What is significant is the high level of acceptance after revision and 
resubmission for all journals. Levels of rejection ranged between 20 and $33 \%$ for all articles received with a mean of $29 \%$.

The findings, in addition to the literature about the subsequent acceptance of manuscripts cited above, suggest that authors of manuscripts should persevere with R\&R in seeking to get published.

\section{Conclusion}

The purpose of the article was to bring together for discussion a selection of issues identified in a descriptive review of academic journal publishing in LIS. In sketching the research and publication landscape research was defined and the need for carefully designed studies in which the perspective, theoretical framework, methodology and tools are in harmony was noted. The primary goals of research and publication were described and the variety of channels available for publication outlined.

Criteria for the evaluation of journal and journal articles quality were addressed. Academic and professional publication options in the LIS field as well as an alleged academic research versus practitioner gap were identified. The potential of evidence-based librarianship in bridging this divide as an area for research and publication was described.

Electronic publishing and electronic access to journal articles were examined and problems noted such as the high cost of access as well as potential areas of benefit to authors such as improved citation from the availability of preprints, and options for multimedia article formats.

Motivations for publishing in academic journals and the role of research and publication in networking were given. Reasons for not publishing and some possible remedies were suggested. Information about rejection rates and the commonly cited reasons for rejection, as well as the acceptance of articles after revision and resubmission were given. Drawing on the case study of selected South African LIS journals, the article gave evidence of low outright acceptance rates, but high acceptance rates for manuscripts after revision and resubmission. In this way persevering with the revision and resubmission of research manuscripts was supported as a reasonable practice, rather than being "beyond reason" as Murray (2005) suggests.

\section{Acknowledgements}

The author thanks the editors for the responses to the survey, and two anonymous referees, the editor and colleagues for critical comments.

\section{References}

Alexander, A. 200I. The manuscript submission process. In. Alexander, A. and W.J. Potter. (eds). 200I. How to publish your communication research: an insider's guide. Pp.I-II.

Alexander, A. and W.J. Potter. (eds). 200I. How to publish your communication research: an insider's guide. London: Sage.

Altmann, K.G. and G.E. Gorman. 1999. The relevance of "cited by leading journal" to serials management in Australian University libraries. Australian library journal 48 (2): I0I-II 5.

Ashcroft, L. and C. Langdon. 1999. Electronic journals and university library collections. Collection building I8(3):।05-I|3.

Booth, A. 2003. Bridging the research-practice gap? The role of evidence-based librarianship. The new review of information and library research $9(1): 3-23$.

Calvert, P.J. and G.E. Gorman. 2002. Testing article quality in LIS journals: the search continues. Paper presented at the $68^{\text {th }}$ IFLA Council and General Conference August 18-24. Available at $h t t p: / / w w w . i f l a . o r g / / V / i f l a 68 / p r o g 02 . h t m$. Accessed 12 December 2005.

Case, D.O. 2002. Looking for information: a survey of research on information seeking, needs and behaviour. Amsterdam: Academic Press.

Cohen, L., Manion, L. and K. Morrison. 2000. Research methods in education. 5th ed. London: Routledge.

Cronin, B. 200I. Peer review and the stuff of scholarship. Library journal I26 (I5):57.

Darch, C. and P.G. Underwood. 2005. Are pre-compiled citation indexes of peer-reviewed journals an adequate control for research quality? A case study of library and information science. South African journal of libraries and information science $7 \mathrm{I}(\mathrm{I}): 1-10$.

Day, A. 2000. How to get research published in journals. Aldershot: Gower.

Dick, A.L. 1993. Three paths to inquiry in library and information science: positivistic, constructivist and critical theory approaches. South African journal of library and information science 6I (2): 53-60.

Garfield, E. 1994a. The ISI impact factor. Current contents June 20. Available at http://scientific.thomson.com/free/essays/ journalcitationreports/impactfactor/ Accessed 24 January 2006.

Garfield, E. 1994b. Using the ISI impact factor. Current contents July I8. Available at http://scientific.thomson.com/free/essays/ journalcitationreports/usingimpactfactor/ Accessed 24 January 2006

Geslin, N. 2002. Investigation into the acquisition of scholarly resources at University of Natal libraries. Unpublished report. Pietermaritzburg: University of Natal.

Griffiths, P. 2002. Evidence informing practice: introducing the mini-review. British journal of community nursing 7(I):39-40. 
Harnad, S., Carr, L., Brody, T. and C. Oppenheim. 2004. Mandated online RAE CVs linked to university eprint archives: enhancing UK research impact and assessment. Ariadne 35:1-13. Available at http://www.ariadne.ac.uk/issue35/harnad/ Accessed April 2004.

Holmes, A. and C. Oppenheim. 200I. Use of citation analysis to predict the outcome of the 200I Research Assessment Exercise for the Unit of Assessment (UoA) 61: Library and Information Management. Information research 6(2):I-23. Available at http://informationr.net/ir/6-2/paper 103.html Accessed April 2004.

Lamoral, D. 200I. An evaluation of information provision at the Institute for Commercial Forestry Research, South Africa: the findings of an information audit. Journal of librarianship 33(4): I77-190.

Maponya, P.M. 2005. Fostering the culture of knowledge sharing in Higher Education. South African journal of higher education 19(5), forthcoming.

McNicol, S. and P. Dalton. 2004. Striking a balance: priorities for research in LIS. Library review 53(3): I67-I 16.

Moran, G. 1998. Silencing scientists and scholars in other fields: power, paradigm controls, peer review, and scholarly publishing. London: Ablex.

Mouton, J. 200I. How to succeed in your Master's and Doctoral studies. Pretoria: van Schaik.

Murray, R. 2005. Writing for academic journals. Maidenhead: Open University Press.

Neuman, W.L. 2003. Social research methods. $5^{\text {th }}$ ed. Boston: Pearson Education.

Ocholla, D.N. 2000. Research capacity in library and information science in South Africa - an overview. Paper delivered at the $66^{\text {th }}$ IFLA Council and General Conference, Jerusalem, 13-18 August.

Ocholla D.N. 2004. An infometric study on aspects of the research output in library and information science in South Africa: 1993-200I. A paper presented at the 4th LIASA Conference, RETIG, 22nd - 26th September 3 , Rustenburg, South Africa

Ocholla, D.N. 2005. Management of LIS journals: some African perspectives. In: L.O. Aina, A.A.Alemna and I. Mabawonku (eds). Improving the Quality of Library and Information Science Journals in West Africa: A Stakeholders' Conference. Proceedings of the Conference Held at the Conference Centre, University of Ibadan, Nigeria ,7-8th December, 2005. I- 8

Orna, L. 1995. Information products in need of information management. Managing information 2(I 2): 22-25.

Pather, R. A comparative study of the costs and benefits of journal ownership versus full-text access in the Faculty of Science at the University of Natal, Durban, Libraries. Master of Information Studies thesis. Pietermaritzburg: University of KwaZuluNatal.

Potter, J. 200I. Avoiding writing traps. In: Alexander, A. and W.J. Potter. (eds). 200 I. How to publish your communication research: an insider's guide. Pp. I3-22.

Powell, R.R., L.M. Baker and J.J. Mika. 2002. Library and information science practitioners and research. Library and information science research 24:49-72.

Prior, A. 2001. Acquiring and accessing serials information: the electronic intermediary. Interlending and document supply 29(2):62-68.

Spurret, D. 2004. Research profile of the University of KwaZulu-Natal: an open access proposal. Unpublished paper. eTekwini: University of KwaZulu-Natal, Howard College, Philosophy.

Testa, J. 2004. The Thomson Scientific journal selection process. Available at http://scientific.thomson.com/free/essays/ selectionofmaterial/journalselection/ Viewed 24 January 2006.

Thomson Scientific. 2005. Welcome to Thomson Scientific. Available at http://www.isinet.com. Viewed 24 January 2006.

Turner, K.J. 2002. Do information professionals use research published in LIS journals? Paper presented at the $68^{\text {th }}$ IFLA Council and General Conference August 18-24. Available at http://www.ifla.org/IV/ifla68/prog02.htm. Viewed I2 December 2005.

University of KwaZulu-Natal (UKZN). Research Office. 2005. Productivity pay-out. Durban: UKZN.

Weller, A.C. 200I. Editorial peer review: its strengths and weaknesses. Medford: American Society for Information Science and Technology.

Zeldin, T. 2005. The future of networking. Available at http://www.oxfordmuse.com/museideas/networkfuture.htm Viewed 2 I January 2005. 